\title{
THE EFFECT OF AGE, HEAD RESISTANCE, AND OTHER PHYSICAL FACTORS ON THE STIMULUS THRESHOLD OF ELECTRICALLY INDUCED CONVULSIONS *
}

BY

\author{
DONALD WATTERSON, Lieut.-Colonel, R.A.M.C.
}

(ReCEIVED 1St SePtember, 1945)

\begin{abstract}
Introduction
By a coincidence, mains alternating current possesses the characteristics which are required to stimulate the cerebral cortex, a comparatively low frequency and a long rising phase of current pulse (Wyss and Obrador, 1937; Fulton, 1938). For this reason electric convulsion therapy requires simple apparatus. Cerletti and Bini (1939) were the first to practise the treatment abroad, and the technique was introduced into this country the following year (Shepley and McGregor, 1939; Fleming et al., 1939).

Large electrodes are used and they are placed on the temples, because it is thought that this position will most effectively stimulate the premotor areas, and also keep the stimulus away from the midbrain and medulla. With the high voltages used, however, the whole brain is stimulated wherever the electrodes are placed; but the customary electrode placement is best retained since it is convenient, and also standardizes technique among different workers.

The theoretical potential necessary to stimulate the brain through its coverings is about 100 volts (Golla et al., 1940), and this agrees with the range that has been used in treatment, 70 to 150 volts. Using 50-cycle alternating current a stimulus of at least 0.05 seconds is necessary, that is five stimuli. It has been shown that one stimulus only, no matter how strong, is insufficient to set up a major convulsion (Hemphill and Walter, 1941). It is unusual to require a longer duration of stimulus than $0 \cdot 30$ second.
\end{abstract}

One of the problems of electrically induced convulsions is the variation in threshold from patient to patient. This is mentioned by authors, but neither causes nor correlates have been found, chiefly because there has been no systematic search for them. Because of this variation in threshold it is necessary to be able to vary the intensity of the stimulus. This may be done by altering either voltage or duration of stimulation. Sogliani (1939) used one voltage, 110 volts, and varied the duration of stimulation. Kalinovsky (1939) used a stimulus of fixed duration ( $0 \cdot 10$ second) and manipulated

* The experiments described in this paper were part of an M.D. thesis read at Cambridge University in April, 1942. voltage. Most workers vary both duration and voltage, beginning treatment with a low-voltage stimulus of brief duration, and increasing both until the convulsion threshold is reached.

The inter-electrode resistance is fairly constant in the same patient, but varies from a few hundred to $2,000 \mathrm{ohms}$ from patient to patient. In the early days of treatment it was assumed that the convulsion threshold must be correlated with the head resistance. Accordingly apparatus was designed so that the stimulating voltage was pre-set during head resistance measurement. This practice was given up when it was realized that a subject of low head resistance might have a high convulsion threshold or vice versa. It was denied that a true correlation existed between head resistance to low-voltage A.C. and the convulsion threshold (Hemphill and Walter, 1941). This lack of correlation was ascribed to the fact that, to high-voltage A.C., organic tissues do not obey Ohm's law, the current which passes being greater than the calculated current. This is so because of the fall in resistance during the passage of the current.

This paper describes an attempt to find correlates of the convulsion threshold. A source of difficulty is clearly the large number of variables. These are of three categories:-

1. Variables of stimulus, which include potential and duration. Wave-form and frequency are possible variables, but are constant in practice, since a given worker uses the same mains supply and the same apparatus.

2. Variables of patient, such as age, sex, size, head resistance, and other physical variables.

3. Variables of day-to-day practice, e.g. area and position of electrodes, head cleanliness, time of day of stimulation. These may be largely eliminated by standardizing technique, but this is difficult in dealing with men and women.

It was clearly desirable to reduce the number of variables. The technique was as nearly standardized as possible. All the experimental subjects were male. With few exceptions the duration of the psychosis was a few months only. Voltage was kept the same throughout. This left, as important variables, duration of stimulus and the physical variables of the patient. 
The physical variables of the patient which it was finally decided to study were age, head resistance, height, weight, and electrode distance.

\section{Method}

The investigation was carried out on 70 male psychotic subjects from the services, schizophrenics, with the exception of a few depressives with schizophrenic colouring. The subjects were free from gross physical disease, though some were under weight. Convulsive treatment was given on three days a week between 11 and 12 a.m. A light breakfast was given at 8 a.m. None of the patients was given sedatives regularly; in a few cases paraldehyde was allowed, but not less than 12 hours before treatment. The heights and weights used were those recorded at the medical examination on entry into the Forces. Inter-electrode distances were measured with callipers. The apparatus used was of the standard pattern constructed by the Edison Swan Electric Co. Head resistance was measured to the nearest $50 \mathrm{ohms}$ before and after stimulation, using the low voltage circuit provided for this purpose $(0.5$ volts A.C.). The same stimulating voltage was used throughout the experiments, 80 arbitrary units on the potentiometer scale, corresponding to 136 volts A.C.

The voltage was calibrated using a high-resistance voltmeter inserted into the secondary circuit. The time (duration) switch was calibrated using an oscillograph. It was found that the contacts had been set slightly inaccurately. The necessary minor corrections of stimulus durations have not been made in the text and in Table III. They are shown below for reference:-

Table 1.-Stimulus Durations: Seconds

\begin{tabular}{c|c}
\hline $\begin{array}{c}\text { (a) As given in text and } \\
\text { in Table III }\end{array}$ & (b) Exact \\
\hline 0.30 & 0.28 \\
0.25 & 0.24 \\
0.20 & $0 \cdot 19$ \\
0.15 & $0 \cdot 15$ \\
0.10 & 0.10 \\
0.05 & 0.06 \\
\hline
\end{tabular}

On the first day of treatment all patients were given an initial stimulus of 0.15 second duration. On the following and subsequent days of treatment the duration was appropriately increased or decreased until the convulsion threshold duration was determined, as shown in the following examples:-

Table II.-Determination of Convulsion Threshold Duration of Stimulus

\begin{tabular}{|c|c|c|c|c|}
\hline \multirow[b]{2}{*}{$\begin{array}{l}\text { Day of } \\
\text { treatment }\end{array}$} & \multicolumn{2}{|c|}{ 1st subject } & \multicolumn{2}{|c|}{ 2nd subject } \\
\hline & $\begin{array}{l}\text { Stimulus } \\
\text { duration } \\
\text { (sec.) }\end{array}$ & $\begin{array}{l}\text { Result of } \\
\text { stimulus }\end{array}$ & $\begin{array}{c}\text { Stimulus } \\
\text { duration } \\
\text { (sec.) }\end{array}$ & $\begin{array}{l}\text { Result of } \\
\text { stimulus }\end{array}$ \\
\hline 1st & $\begin{array}{l}0 \cdot 15 \\
0 \cdot 20 \\
0 \cdot 25\end{array}$ & $\begin{array}{l}\text { No fit } \\
\text { No fit } \\
\text { Fit }\end{array}$ & $0 \cdot 15$ & Fit \\
\hline 2nd & $\begin{array}{l}0 \cdot 20 \\
0 \cdot 25 \\
0 \cdot 30\end{array}$ & $\begin{array}{l}\text { No fit } \\
\text { No fit } \\
\text { Fit }\end{array}$ & $0 \cdot 10$ & Fit \\
\hline $3 r d$ & $0 \cdot 25$ & Fit & 0.05 & Fit \\
\hline 4 th & $\begin{array}{l}0 \cdot 20 \\
0 \cdot 25\end{array}$ & $\begin{array}{l}\text { No fit } \\
\text { Fit }\end{array}$ & $\begin{array}{l}0.025 \\
0.05\end{array}$ & $\begin{array}{l}\text { No fit } \\
\text { Fit }\end{array}$ \\
\hline $\begin{array}{l}\text { Threshold } \\
\text { duration }\end{array}$ & \multicolumn{2}{|c|}{$0.25 \mathrm{sec}$. } & \multicolumn{2}{|c|}{$0.05 \mathrm{sec}$} \\
\hline
\end{tabular}

It will be seen that, if on any occasion an initial stimulus of less than the convulsion threshold duration was applied, it was followed (after a few minutes) by one or more stimuli of longer duration, in an attempt to elicit a convulsion (since the essence of the treatment is the production of convulsions). All results recorded in Fig. 1 and Table III refer only to the initial stimulus on any day of treatment. By the method described, the threshold duration of stimulus for the production of a convulsion is usually found within a week, and always within 10 days, of commencing treatment.

\section{Sources of Error}

1. Day-to-day variations in mains voltage (extreme variation about 12 per cent.).

2. Variations in voltages in the secondary circuits of the apparatus, due to temperature changes of the potentiometer.

3. Day-to-day variations of convulsion threshold.

4. Day-to-day variations of head resistance. These are slight if technique is standardized.

\section{Results}

Initial head resistances ranged from 100 to 1,750 ohms. Their distribution is shown in Fig. 1. Three-quarters of the head resistances fell between

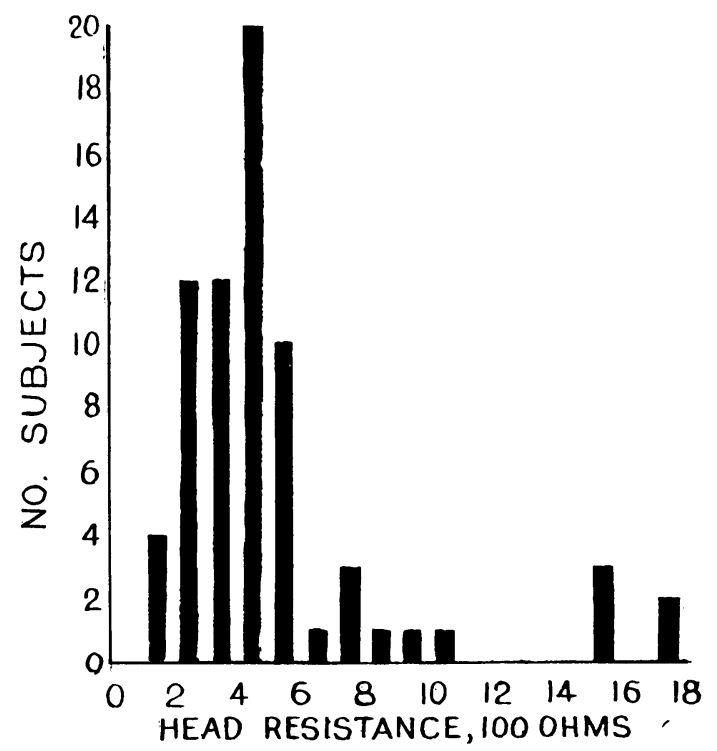

FIG. 1.-Distribution-head resistances.

200 and 600 ohms, the greatest number occurring at 400 ohms. The five high-resistance subjects appeared to form a separate group. This peculiar distribution of head resistances has been described before (Golla et al., 1940) and is unexplained. Head resistance fell after stimulation in all but three subjects whether a fit occurred or not. The extent of this fall varied from 0 to $1,250 \mathrm{ohms}$. The greater the initial resistance the greater the fall (Fig. 2). The cause of the fall in head resistance during stimulation is unknown; it has been postulated as being due to local skin changes beneath the electrodes. It has been maintained that this fall is responsible for the apparent lack of corre- 
lation between initial head resistance and convulsion threshold, but the straight line curve of Fig. 2 refutes this.

Head resistances quoted in Table III refer to the pre-stimulation resistances on the occasions when the threshold durations were determined. Threshold

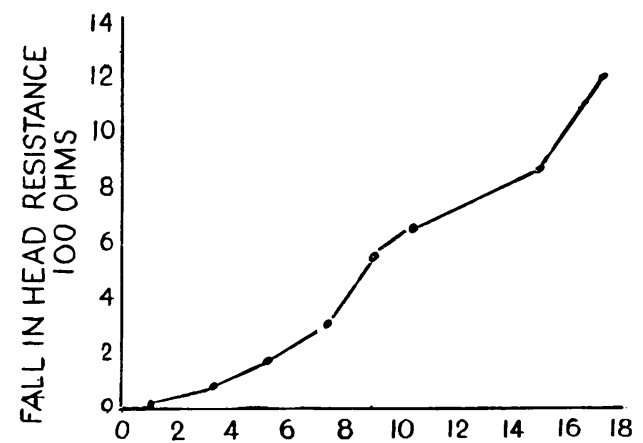

PRESTIMULATION HEAD RESISTANCE, 100 OHMS

FIG. 2.-Relation-initial head resistance to fall in resistance during stimulation.

durations ranged between 0.05 and 0.03 second, 94 per cent. lying between $0 \cdot 10$ and 0.25 second. The threshold was redetermined from time to time in 45 subjects who were given treatment over a period of weeks. In 22 the threshold remained constant, in 12 it rose by 0.05 second, and in 2 by more than 0.05 second; in 8 it fluctuated by 0.05 second above and below the initial threshold; and in one it fell. Curves $(a),(b),(c)$, Fig. 3, illustrate the com-

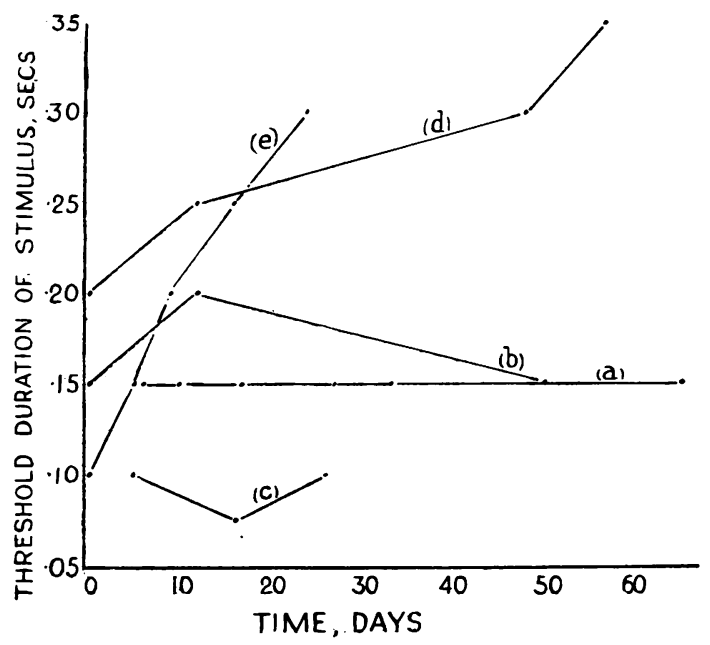

FIG. 3.-Changes in threshold duration of stimulus during treatment.

moner types of threshold variation. Curve $(d)$ is exceptional in the degree of increase continued over a long period. Curve $(e)$ is even more unusual, and the only one of its kind among the patients investigated. It occurred in a catatonic schizophrenic who made a good recovery during the course of treatment. (No statistical correlation was found, however, between improvement in the mental state and increase of threshold during treatment.)

In the remainder of the paper threshold refers in all cases to the first determined threshold duration. The distributions of thresholds in relation to height, weight, and inter-electrode distance respectively, proved to be random.

The ages, head resistances, and thresholds of the subjects are arranged in Table III.

Table III. - The Ages, Head Resistances, and THRESHOLd DURATIONS OF StIMULUS IN THE 70 SUBJECTS

\begin{tabular}{|c|c|c|c|c|c|}
\hline Age & \begin{tabular}{|c|} 
Head \\
resistance \\
$($ ohms $)$
\end{tabular} & $\begin{array}{c}\text { Threshold } \\
\text { (secs.) }\end{array}$ & Age & $\begin{array}{c}\text { Head } \\
\text { resistance } \\
\text { (ohms) }\end{array}$ & $\begin{array}{c}\text { Threshold } \\
\text { (secs.) }\end{array}$ \\
\hline $\begin{array}{l}19 \\
19 \\
19 \\
20 \\
20 \\
20 \\
20 \\
21 \\
21 \\
21 \\
21 \\
22 \\
22 \\
22 \\
22 \\
22 \\
22 \\
22 \\
22 \\
23 \\
23 \\
23 \\
23 \\
23 \\
24 \\
24 \\
24 \\
24 \\
25 \\
25 \\
25 \\
25 \\
25 \\
25 \\
25 \\
\mathbf{y}\end{array}$ & $\begin{array}{r}500 \\
400 \\
400 \\
200 \\
500 \\
500 \\
1,500 \\
750 \\
1,000 \\
450 \\
400 \\
400 \\
400 \\
450 \\
400 \\
300 \\
600 \\
250 \\
300 \\
800 \\
200 \\
400 \\
150 \\
400 \\
500 \\
700 \\
1,000 \\
200 \\
300 \\
500 \\
150 \\
300 \\
300 \\
350 \\
250\end{array}$ & $\begin{array}{l}0 \cdot 2 \\
0 \cdot 15 \\
0 \cdot 1 \\
0 \cdot 1 \\
0 \cdot 15 \\
0 \cdot 1 \\
0 \cdot 15 \\
0 \cdot 25 \\
0 \cdot 25 \\
0 \cdot 15 \\
0 \cdot 2 \\
0 \cdot 1 \\
0 \cdot 1 \\
0 \cdot 1 \\
0 \cdot 2 \\
0 \cdot 15 \\
0 \cdot 2 \\
0 \cdot 1 \\
0 \cdot 15 \\
0 \cdot 15 \\
0 \cdot 15 \\
0 \cdot 15 \\
0 \cdot 05 \\
0 \cdot 2 \\
0 \cdot 1 \\
0 \cdot 2 \\
0 \cdot 15 \\
0 \cdot 1 \\
0 \cdot 2 \\
0 \cdot 15 \\
0 \cdot 1 \\
0 \cdot 1 \\
0 \cdot 15 \\
0 \cdot 15 \\
0 \cdot 1\end{array}$ & $\begin{array}{l}26 \\
26 \\
26 \\
26 \\
26 \\
27 \\
27 \\
27 \\
28 \\
28 \\
28 \\
28 \\
28 \\
29 \\
29 \\
29 \\
29 \\
30 \\
31 \\
31 \\
32 \\
32 \\
32 \\
33 \\
34 \\
34 \\
36 \\
36 \\
38 \\
39 \\
40 \\
42 \\
42 \\
43 \\
49\end{array}$ & $\begin{array}{r}150 \\
250 \\
300 \\
1,500 \\
200 \\
300 \\
1,750 \\
400 \\
400 \\
250 \\
1,500 \\
450 \\
400 \\
250 \\
100 \\
450 \\
500 \\
450 \\
250 \\
600 \\
500 \\
350 \\
700 \\
1,750 \\
300 \\
250 \\
450 \\
400 \\
900 \\
350 \\
400 \\
200 \\
550 \\
300 \\
400\end{array}$ & $\begin{array}{l}0 \cdot 15 \\
0 \cdot 1 \\
0 \cdot 15 \\
0 \cdot 2 \\
0 \cdot 2 \\
0 \cdot 15 \\
0 \cdot 25 \\
0 \cdot 15 \\
0 \cdot 15 \\
0 \cdot 15 \\
0 \cdot 25 \\
0 \cdot 1 \\
0 \cdot 2 \\
0 \cdot 15 \\
0 \cdot 2 \\
0 \cdot 2 \\
0 \cdot 3 \\
0 \cdot 2 \\
0 \cdot 15 \\
0 \cdot 15 \\
0 \cdot 2 \\
0 \cdot 2 \\
0 \cdot 1 \\
0 \cdot 3 \\
0 \cdot 2 \\
0 \cdot 2 \\
0 \cdot 25 \\
0 \cdot 25 \\
0 \cdot 3 \\
0 \cdot 2 \\
0 \cdot 2 \\
0 \cdot 2 \\
0 \cdot 25 \\
0 \cdot 15 \\
0 \cdot 25\end{array}$ \\
\hline
\end{tabular}

The following results emerge from statistical treatment of these data:-

1. Tetrachoric correlations, using Burt's Short Method, have been calculated as other methods are impossible because of the small numbers and the types of scatter.

$$
\begin{array}{ll}
\text { (a) } \frac{r}{\text { Threshold } \times \text { Age }} & =0.52 \pm 0.10 \\
\text { (b) } \frac{r}{\text { Threshold } \times \text { Head resistance }} & =0.44 \pm 0.11 \\
\text { (c) } \frac{r}{\text { Age } \times \text { Head resistance }} & =0.08
\end{array}
$$

Of these correlations, that between threshold and age and that between threshold and head resistance are significant. The critical ratio of $(a)$ is $5 \cdot 2$ and of $(b)$ is $4 \cdot 0$. Any correlation for 70 cases is 
regarded as very significant with a $t$ of over 2.648 . The correlation between age and head resistance is of negligible size and has probably arisen by chance.

2. If a test of linearity is applied to the scatter of age and threshold the correlation ratio comes to 0.476 (Guilford, 1936). Since this is actually less than the coefficient of correlation $(0.52)$ it is reasonable to conclude that the relationship is linear.

3. The multiple correlation coefficient of age and head resistance against threshold is 0.655 . The index of forecasting efficiency for the correlation between age and threshold is 14 per cent. (Guilford, 1936). This means that an attempt to predict thresholds from ages will succeed in 14 per cent. of the cases better than pure chance. When the factor of head resistance is also taken into account the forecasting efficiency is raised to 24.5 per cent. Thus more factors than age and head resistance determine the threshold, but it is impossible to draw any conclusions about the number, character, and size of the remaining factors.

\section{Discussion}

It is surprising that none of the factors relating to size was found to be correlated with threshold. Body weights vary from time to time, particularly in those subject to mental disorders, and this may be a source of confusion. On the other hand, height and inter-electrode distance are always the same in the same subject. The variations in height (60 to 73 in.) and in inter-electrode distance ( $5 \cdot 1$ to 6.0 in.) are relatively less than the variations in age (19 to 49 years) and head resistance (100 to 1,750 ohms); it is possible that small variations in threshold with variations in height and size of head would not be revealed by the technique adopted.

The positive correlation between the convulsion threshold and the pre-stimulation head resistance suggests that the latter is directly related to the head resistance during the passage of the stimulus. If this is the case, then such a correlation might be expected. That it has not previously been shown is partly because other variables tended to conceal it, and partly because the dramatic fluctuations in head resistance during electrical stimulation misled workers into supposing that such variations were unpredictable.

The finding that convulsion threshold is correlated with age may have one of three meanings: (a) Men with a low convulsion threshold contract schizophrenia early in life, those with a high threshold later, in a proportionate manner. This is not supported by the fact that there is no correlation between increase of the threshold during treatment and improvement in the mental state. (b) Young schizophrenics have a low electric convulsion threshold, older schizophrenics correspondingly higher. This cannot be ruled out, but if it were so we should expect convulsions of all kinds to be more common among younger than among older schizophrenics in a manner different from the rest of the population; and this is not so. (c) The finding is not specific to psychotic subjects but reflects a linear correlation between age and convulsion threshold among the general population over the ages investigated. This increase of threshold with age might be caused either by a change in the superficial tissues of the head, or by a change in the brain itself. If it were caused by a change in the covering tissues there should be a positive correlation between age and head resistance; but this is not so. The conclusion is that it is caused by the brain becoming increasingly obdurate to the electrical induction of convulsions as age increases.

Other changes in the C.N.S. with age have been described. Fröhlich and Mirsky (1942) showed that young rats, up to 17 days old, were more susceptible to convulsions from acid fuchsin injection than older animals. They referred to other evidence that the C.N.S. of the immature organism differs from that of the mature. Children are more liable to convulsions than adults. Certain acid dyes pass into the brains and C.S.F. of children, but not of adults. The brains of children dying of jaundice are yellow, those of adults colourless. The herpes virus (Andervont, 1929) and the equine encephalomyelitis virus (Sabin and Olitsky, 1935) produce reactions in the brains of young animals, but not in those of adults. The fatal dose of certain drugs, such as morphine, is less in young animals than in adults (Döbeli, 1911; Clark, 1912; Eddy, 1939). All these findings refer to differences between immature and mature organisms, and are not strictly parallel with the finding that the electrical convulsion threshold is correlated with age.

Heppenstall and Hill (1943) have reported that the liability to develop an abnormal EEG following a head injury is significantly greater if the injury occurs before the age of 20 years than subsequently. Similarly, the incidence of certain C.N.S. diseases diminishes during adult life, and most important in this connection is epilepsy. However, although the incidence of epilepsy decreases after adolescence, there is no evidence that in general the frequency of fits in proven epileptics falls over the same period. Golla et al. (1937) found that the percentage of abnormal EEGs among epileptics appeared to decrease in later adult life, and Walter (1938) reported that the disappearance of the EEG abnormality at about the age of 40 years had actually been watched in certain epileptics.

Studies of normal ageing processes in relation to the C.N.S. have been concerned almost entirely with the period of senescence. Thus Critchley (1939), in his review of this topic, makes no reference to earlier periods of life, except in relation to pathological material. The psychological aspects of ageing, on the other hand, have been studied in all age groups. Miles (1939) has given an excellent review of the subject. Performance at most tests or occupations shows characteristically an increase in speed and efficiency up to a certain age and thereafter a decline. There are wide individual variations. Performance involving the maximum of motor activity and the minimum of abstract 
thinking (e.g. running) reaches a peak of efficiency early in life, psychomotor activity (e.g. reacting to a signal) later, and purely psychological activity (e.g. philosophical speculation) in middle life or even old age. Not least of the features of ageing in the middle span of life is a slow but profound alteration of behaviour and personality. This is discussed in relation to the normal by Hamilton (1939), but it is more conspicuous in the abnormal. Thus criminal and psychopathic behaviour of all kinds dwindles throughout this age period. It has been shown that psychopathic behaviour is associated with abnormal electrical activity of the cortex (Hill and Watterson, 1942). Recently Sulzbach et al. (1943) have claimed that this kind of abnormal EEG is associated with a low electrical convulsion threshold. There is thus a chain of evidence, linking changes of behaviour through the middle years of life with a slowly decreasing sensitivity of the C.N.S. to electrical insult over the same period. This is fertile territory for speculation.

Nothing is known with certainty about other factors than head resistance and age which affect the electrical convulsion threshold since there has been little work done on this problem. What few conclusions there are have been based rather on impressions than on statistically proved relationships. Thus Nussbaum (1943) feels that less current is needed to cause convulsions in patients who submit willingly to the treatment. He believes that women require more current than men for this reason. This suggestion is worth careful investigation. Nussbaum agrees with the finding that the size of skull is unimportant in determining threshold.

\section{Summary}

1. Using a constant stimulating voltage the threshold duration of stimulus for induced convulsions was determined in 70 psychotic subjects.

2. Convulsion threshold was found not to be correlated directly with height, weight, or size of head (inter-electrode distance).

3. A positive correlation was found between threshold and head resistance, and between threshold and age, but not between age and head resistance. There is no reason to suspect that the relation between threshold and age is not linear.

4. Convulsion threshold is determined by more factors than age and head resistance, but the data permit no speculation about the nature, number, or importance of these other factors.

5. A parallel is drawn between the rise in the electrical convulsion threshold of the C.N.S. during the third and fourth decades of life and increasing stability of behaviour over the same period.

My thanks are due to Lieut.-Colonel A. A. W. Petrie, C.B.E., in whose hospital the experiments were performed; and to Lieut.-Colonel G. Trist and Sergeant J. C. Daniels for the statistical analysis of the data.

\section{REFERENCES}

Andervont, H. B. (1929). J. infect. Dis., 44, 383.

Cerletti, U., and Bini, L. (1939). Boll. Acad. Med. Rom., $64,36$.

Clark, A. J. (1912). Quart. J. exp. Physiol., 5, 385.

Critchley, M. (1939). In Problems of Ageing. Edited by E. V. Cowdry. London, Balliere, Tindall and Cox, p. 483.

Döbeli, H. E. (1911). Monatschr. Kinderh., 9, 397.

Eddy, N. B. (1939). J. Pharmacol., 66, 182.

Fleming, G. W. T., Golla, F. L., and Walter, W. G. (1939). Lancet, 2, 1353.

Fröhlich, A., and Mirsky, I. A. (1942). Arch. Neurol. Psychiat., 47, 30.

Fulton, J. F. (1938). Physiology of the Nervous System. London, Oxford Univ. Press, 410.

Golla, F. L., Graham, S., and Walter, W. G. (1937). J. ment. Sci., 83, 137.

Walter, W. G., and Fleming, G. W. T. (1940). Proc. roy. Soc. Med., 33, 261.

Guilford, J. P. (1936). Psychometric Methods. New York, McGraw-Hill Book Co., 346 and 362.

Hamilton, G. V. (1939). In Problems of Ageing. Edited by E. V. Cowdry. London, Ballière, Tindall and Cox, 463.

Hemphill, R. E., and Walter W. G. (1941). J. ment. Sci., 87, 256.

Heppenstall, M. E., and Hill, D. (1943). Lancet, 1, 261. Hill, D., and Watterson, D. (1942). J. Neurol. Psychiat., $5,47$.

Kalinovsky, L. (1939). Lancet, 2, 1232.

Miles, W. R. (1939). In Problems of Ageing. Edited by E. V. Cowdry. London, Ballière, Tindall and Cox, 535.

Nussbaum, K. (1943). Psychiatric Quarterly, 17, 327.

Sabin, A. B., and Olitsky, P. K. (1938). Proc. Soc. exp. Biol., 38, 595 .

Shepley, W. H., and McGregor, J. S. (1939). Brit. med. J., 2, 1269.

Sogliani, G. (1939). Rass. Studi. psychiat., 28, 4.

Sulzbach, W., Tillotson, K. J., Guillemin, V., and Sutherland, G. F. (1943). Amer. J.'Psychiat., 99, 519.

Walter, W. G. (1938). J. Neurol. Psychiat., 1, 359.

Wyss, O. A. M., and Obrador, Alcalde S. (1937). Amer. J. Physiol., 120, 42. 